\title{
Commitment or entrenchment? Convergent and discriminant validation of affective and continuance dimensions of the three-component model
}

\author{
Ana Carolina de Aguiar Rodrigues \\ Management, School of Economics, Business and Accounting, \\ University of São Paulo, São Paulo, Brazil \\ Antonio Virgílio Bittencourt Bastos \\ Psychology, Federal University of Bahia, Salvador, Brazil \\ Daniela Campos Bahia Moscon \\ Management, Federal University of Bahia, Salvador, Brazil, and \\ Giselle Cavalcante Queiroz \\ Management, School of Economics, Business and Accounting, \\ University of São Paulo, São Paulo, Brazil
}

Commitment or entrenchment in the TCM model?

Received 19 October 2020 Revised 25 February 2021 Accepted 19 April 2021

\begin{abstract}
Purpose - Is it possible to consider organizational entrenchment $(\mathrm{OE})$ and continued commitment $(\mathrm{CC})$ as the same phenomenon? Are there enough differences between $\mathrm{CC}$ and affective commitment $(\mathrm{AC})$ to defend that they cannot be part of the same construct? The objective of this study was to examine the convergence of validated measures between $\mathrm{OE}$ and $\mathrm{CC}$ and their discrimination to $\mathrm{AC}$. The authors' aim was to compare two models of antecedents and their consequences: the model that includes $\mathrm{OE}$ and $\mathrm{AC}$, and the one that includes CC and $\mathrm{AC}$.

Design/methodology/approach - An extensive cross-sectional study was conducted with a sample of 1,648 respondents (the majority lived in the Northeast region of Brazil, worked in private services companies, were female, single, under 35 years old, had, at least, begun college studies and received up to five times the minimum wage). A six-point Likert scale was used in this study. To measure $\mathrm{OE}, \mathrm{CC}$ and $\mathrm{AC}$, the authors used reduced versions of validated measures. To test the hypotheses, first, the authors used Pearson's correlation analysis and then, structural equation modeling, comparing two models of antecedents and consequences (one including $\mathrm{OE}$ and $\mathrm{AC}$, and the other, including $\mathrm{CC}$ and $\mathrm{AC}$ ).

Findings - As expected, affective commitment had a positive impact on the desired behavior (intention for commitment, defense, staying), whereas entrenchment and continuance commitment had a negative or nonsignificant impact on these behaviors. Results show the existence of a conceptual and empirical overlap between organizational entrenchment and continuance commitment and indicate that the continuance dimension is not part of commitment but rather part of organizational entrenchment.

Research limitations/implications - The fact that this is a cross-sectional study sets a limitation on the results, for not allowing greater understanding of the dynamics and the causal direction of relationships.
\end{abstract}

(C) Ana Carolina de Aguiar Rodrigues, Antonio Virgílio Bittencourt Bastos, Daniela Campos Bahia Moscon and Giselle Cavalcante Queiroz. Published in Revista de Gestão. Published by Emerald Publishing Limited. This article is published under the Creative Commons Attribution (CC BY 4.0) licence. Anyone may reproduce, distribute, translate and create derivative works of this article (for both commercial and non-commercial purposes), subject to full attribution to the original publication and authors. The full terms of this licence may be seen at http://creativecommons.org/licences/by/4.0/ legalcode

This research was supported by CAPES scholarships and CNPq research grant.

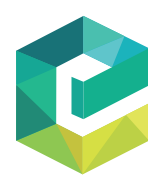

Revista de Gestão Vol. 29 No. 1,2022 pp. $17-38$ Emerald Publishing Limited e-ISSN: $2177-8736$ DOI 10.1108/REGE-10-2020-0090 
REGE 29,1

Additionally, it follows the trend of studies in the organizational behavior field of utilizing self-reported data, which results in problems related to perceptual bias (Morrow, 2011).

Practical implications - The practical implications of this study regard a greater clarification on which behaviors are expected from either committed and entrenched workers, and which drivers may lead to each of these bonds. Therefore, a better understanding of the phenomenon contributes to the training of managers and to the design of organizational policies and practices.

Social implications - The clarity of bonds also allows its application to different contexts beyond business organizations, as a step to reach better understanding of commitment and entrenchment in different settings, economical and national realities.

Originality/value - It is expected that these findings add a higher precision to the research on commitment, thus contributing to the validity of the measures. Given these results and confirmation that OE and CC represent the same bond, it is considered appropriate to designate this type of bond simply as OE. Additionally, the results of this study represent a further argument in favor of prioritizing the AC than CC in research and in management of organizational commitment.

Keywords Organizational commitment, Organizational entrenchment, Continuance commitment

Paper type Research paper

\section{Introduction}

When joining an organization, the worker enters a complex environment, consisting of technical and social structures. Even though the organization may be considered a socially constructed system and constantly changing, it can also take on the role of an entity to which the worker relates. This relationship can be volitional, reflecting dedication and responsibility to the organization (Klein, Molloy \& Brinsfield, 2012). On the other hand, the worker may also notice that there are advantages in continuing the relationship with the organization and that there would be disadvantages to break it. Permanence, when it occurs, may reflect necessity and can be the result of the investments accumulated in one's experience with the organization, in addition to the evaluation of costs and benefits of staying (Rodrigues \& Bastos, 2011b).

These two forms of bond have always been treated as different types, despite the fact that for a long time they have been considered dimensions of the three-component model (TCM) of organizational commitment (Meyer \& Allen, 1991). New studies have suggested that organizational commitment (OC) should be assessed as a one-dimensional construct (Klein, Cooper, Molloy \& Swanson, 2014). Other scholars have suggested the demarcation between these two types, for the purpose of assigning them to different conceptual bodies (Klein \& Park, 2016, Cooper-Hakim \& Viswesvaran, 2005, Solinger, Olffen \& Roe, 2008). To support this separation, we argue that the first bond, long known as affective commitment (AC), is the essence of $\mathrm{OC}$, which should be, in turn, considered a one-dimensional construct. We also argue that the second type of bond, called continuance commitment (CC), becomes part of a construct that explains the permanence of the worker through necessity: organizational entrenchment $(\mathrm{OE})$. This bond refers to the set of investments and arrangements made by the individual in the organization that, if not available in other employment alternatives, could force the individual to stay with the organization.

Rodrigues, Bastos \& Moscon (2019) managed to gather theoretical arguments and empirical evidence to support that $\mathrm{OE}$ and the $\mathrm{CC}$ represent the same psychosocial phenomenon. In a recent handbook organized by Meyer (2016), both possibilities (uni or multi-dimensional commitment) are discussed (Allen, 2016; Klein \& Park, 2016), as the research on commitment has been experiencing a transition moment on its conceptualization.

To gather arguments in defense of this restructuring, it is essential to first investigate the convergence of validated measures of $\mathrm{CC}$ and $\mathrm{OE}$, as a way of demonstrating the existence of a single phenomenon that until now has been given two denominations. Second, one should evaluate whether, in fact, this phenomenon sufficiently differs from $\mathrm{AC}$, to the point of being 
considered a distinct construct. In the present study, we tested the convergent and discriminant validity of these bonds, by comparing models that incorporate some of its main antecedents and outcomes: perception of employability, human resources management practices and behavioral intentions. The discussion about the relationships between such phenomena and the constructs investigated in this paper will be further explored in the section dedicated to formulating the research hypotheses.

Next, we begin with a brief discussion on conceptual problems with commitment. We present arguments that support the search for empirical evidence toward a greater delineation of $\mathrm{OC}$, with the removal of its continuance basis. We then recover some preliminary evidence of overlap between $\mathrm{CC}$ and $\mathrm{OE}$, and present the approach to validity used for the convergence and divergence tests. Finally, we present the variables of the models to be tested and the hypotheses of the study.

The research contributes to the literature on $\mathrm{OC}$ and demonstrates why $\mathrm{CC}$ cannot be part of the $\mathrm{OC}$ construct. The practical contribution is to allow managers in a more appropriate way to identify the dynamics of employee ties with organizations.

\subsection{Why shouldn't CC be considered part of the commitment construct?}

Over the years, the expansion of the multidimensionality of commitment contributed to what Osigweh (1989) called "concept stretching": what initially seems a gain in terms of extension results in less precise concepts. Rodrigues \& Carvalho-Freitas (2016) also point to overlaps and ambiguities of the commitment concept due to extensions and borrowing processes. To minimize this stretching, Osigweh (1989) proposes that definitions be stated about what the construct is not, thus seeking to arrive at a definition of its boundaries, to a central essence, which has a higher level of abstraction and a wider range of applications.

We argue that commitment does not include the CC based on three main arguments:

(1) This component explains the employee's permanence, a criterion that guided the first commitment studies (Rodrigues \& Bastos, 2010; Klein, Molloy \& Brinsfield, 2012) but that does not consider all the behaviors expected of the committed employee;

(2) The measures developed to assess the $\mathrm{CC}$ still present limits. Studies conducted in various countries consistently reveal lower internal consistency levels (Solinger, Olffen \& Roe, 2008, Cooper-Hakim \& Viswesvaran, 2005). Moreover, since the study by McGee \& Ford (1987), the debate remains about the factor structure of the measure, originally composed of two dimensions, "high personal sacrifice" and "low alternatives." Different authors argue that "low alternatives" is an antecedent and not part of OC (Jaros, 1997; Ko, Price \& Mueller, 1997);

(3) Unlike what is observed for the affective and normative bases, the $\mathrm{CC}$ does not relate to desirable results. Solinger, Olffen \& Roe (2008) gathered evidence that the affective dimension presents more significant relationships with desirable behaviors, such as job performance and organizational citizenship behaviors, and predicts a wider range of positive consequences for the organization and its employees. In contrast, the undesirable results of the continuance dimension, such as absenteeism, neglect and intention to leave, have led some authors (Meyer \& Herscovitch, 2001, Sethi \& King, 1998) to discourage its development.

Based on these arguments, we formulate some thoughts toward a clearer delineation of the commitment construct: Is it possible that, in a single construct, there are factors that are positively related to the desired variables, and a factor that is negatively related to the same variables? If the $\mathrm{CC}$ presents negative relationships with desirable variables and positive ones 
REGE

29,1 with undesirable variables, how can its stimulus possibly contribute to greater OC? Is it coherent to treat as commitment a factor that should be avoided?

It seems that the $\mathrm{CC}$ would be relevant only if $\mathrm{OC}$ was taken strictly as a predictor of the worker staying in the organization. Meyer, Stanley, Herscovitch, and Topolnytsky (2002) state that, although CC presents a non-existent or even negative correlation with desirable behaviors at work, interest in its development should be encouraged in order to avoid it, in the attempt to increase AC. On the other hand, studies focusing on career indicate a strong correlation between $\mathrm{CC}$ and entrenchment. The initial theoretical and empirical evidence broaden the argument that the $\mathrm{CC}$ does not comprise commitment, but $\mathrm{OE}$, as we discuss in the next section.

\subsection{Prior evidence of overlap between $C C$ and $O E$}

Over the past decade, the literature has gathered works that contrasted commitment and entrenchment bonds, initially with a focus on career. Carson, Carson \& Bedeian (1995) defined career entrenchment as the tendency to remain in a profession due to investments, the search for psychological preservation and perception of few career alternatives. Blau (2001a, b) noted that entrenchment had a theoretical basis and conceptual framework similar to the continuance dimension of the three-dimensional model of commitment defined by Meyer, Allen \& Smith (1993). From this insight, Blau \& Holladay (2006), and Blau (2009) conducted studies to examine the overlap between the types of bonds, under the assumption that entrenchment should be considered a dimension for career commitment.

In the organizational focus, studies of overlap between these two bonds are still preliminary. They started after Rodrigues \& Bastos (2012) presented the concept of OE and validated its measure. Rodrigues \& Bastos (2011a) defined OE as the tendency of workers to remain in the organization due to three factors: (1) Individual adjustment to social position, which are the investments of the individual and the organization in the adaptive process and in the conditions necessary for proper performance of the activities; (2) Impersonal bureaucratic arrangements, representing stability and financial gains which would be lost if the worker left the organization; (3) Low alternatives: the individual's perception that there are no other opportunities, either through market constraints or through beliefs that his/her professional profile would not be accepted by other organizations.

The measure of $\mathrm{CC}$ has been the subject of discussions related to the relevance of the "low alternatives" dimension, also present on the scale of OE. Regardless of its factor structure, the results indicate high correlations between both constructs (Rodrigues \& Bastos, 2011b).

Figure 1 summarizes the main evidence that $\mathrm{OE}$ and $\mathrm{CC}$ represent the same phenomenon: (1) both are based on Becker's (1960) theory; (2) they present similar sub-dimensions; (3) they represent an individual's attitude toward a behavior (in this case, to remain in the organization), forming a material bond and staying out of necessity; (4) both show positive correlations between them (Carson, Carson \& Bedeian, 1995; Blau, 2001a) and negative correlations with variables such as performance (Cooper-Hakim \& Viswesvaran, 2005; Scheible, Bastos \& Rodrigues, 2013), considered desirable behaviors for a worker.

We sought to investigate the validity of measures of $\mathrm{OE}$ and $\mathrm{CC}$, to assess their convergence to one another, and their discrimination related to $\mathrm{AC}$. The number of studies on OE have been growing in Brazil (Rodrigues, Bastos \& Moscon, 2019; Silva, Tomazzoni \& Costa, 2018; Milhome, Rowe \& Santos, 2018; Souza, Aguiar \& Carneiro, 2018), mostly related to its overlap with CC, but less on its nomological network. Therefore, we also seek, with this work, to conduct analyses that enable the empirical development of this theoretical model.

\section{Models and hypotheses}

Figure 2 presents two models tested in this study. Our purpose was to compare the nomological networks established by both types of bonds, with other variables, as a strategy 


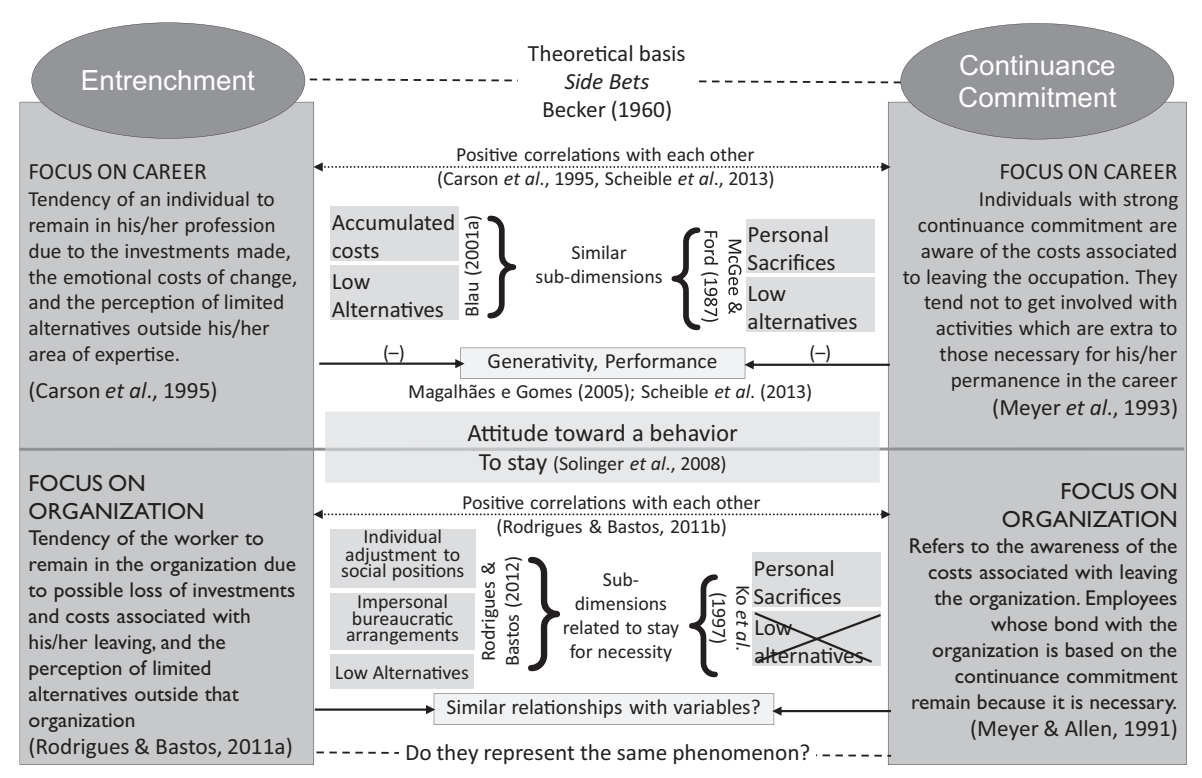

for testing the convergent validation between $\mathrm{CC}$ and $\mathrm{OE}$, and to analyze the discriminant validation between these two and $\mathrm{AC}$. We then tested and compared these two models of antecedents and consequences: the model that includes $\mathrm{OE}$ and $\mathrm{AC}$, and the model that includes $\mathrm{CC}$ and AC. The following sections explain the variables included in the models and the rationale that supports the hypotheses.

\subsection{Perception of employability}

Rothwell \& Arnold (2007) observed that there is some consensus that employability depends on individual attributes, factors internal to the organization, and labor market variables. After a review of the concepts discussed by different researchers, they define employability as the ability that the individual has to keep a job or get a desired job. To this end, individual characteristics such as knowledge, skills, ability to learn, and knowledge of the profession, resilience and self-efficacy are needed. In addition, factors internal to the organization offer the employee opportunities for better positions at work. Also, external factors, such as economic conditions and the labor market, expand or limit one's future employment prospects. A variety of predictors of perceived employability led Rothwell \& Arnold (2007) to emphasize the importance of differentiating, in research studies, those originated internally from those originating outside the organization.

De Cuyper \& De Witte (2011) included the "internal versus external" dyad and added "quality versus quantity" opportunities, in preparing the model of perceived employability. The increase in internal employability in the organization, which refers to the traditional career, depends on both the investments made by the employee and those made by the employer in terms of training, networking, personnel costs, among others. The employee may interpret these investments as a sign that the organization has a long-term interest in his/her stay and thus feels the obligation to reciprocate. According to De Cuyper \& De Witte (2011), mechanisms of compensation in this case could involve loyalty, AC and better performance.

\section{Commitment or entrenchment in the TCM model?}

21

Figure 1.

Summary of evidence $\mathrm{OE}$ and $\mathrm{CC}$ represent the same phenomenon 


\section{REGE}

29,1

\section{2}

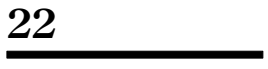

Figure 2.

Models of investigation

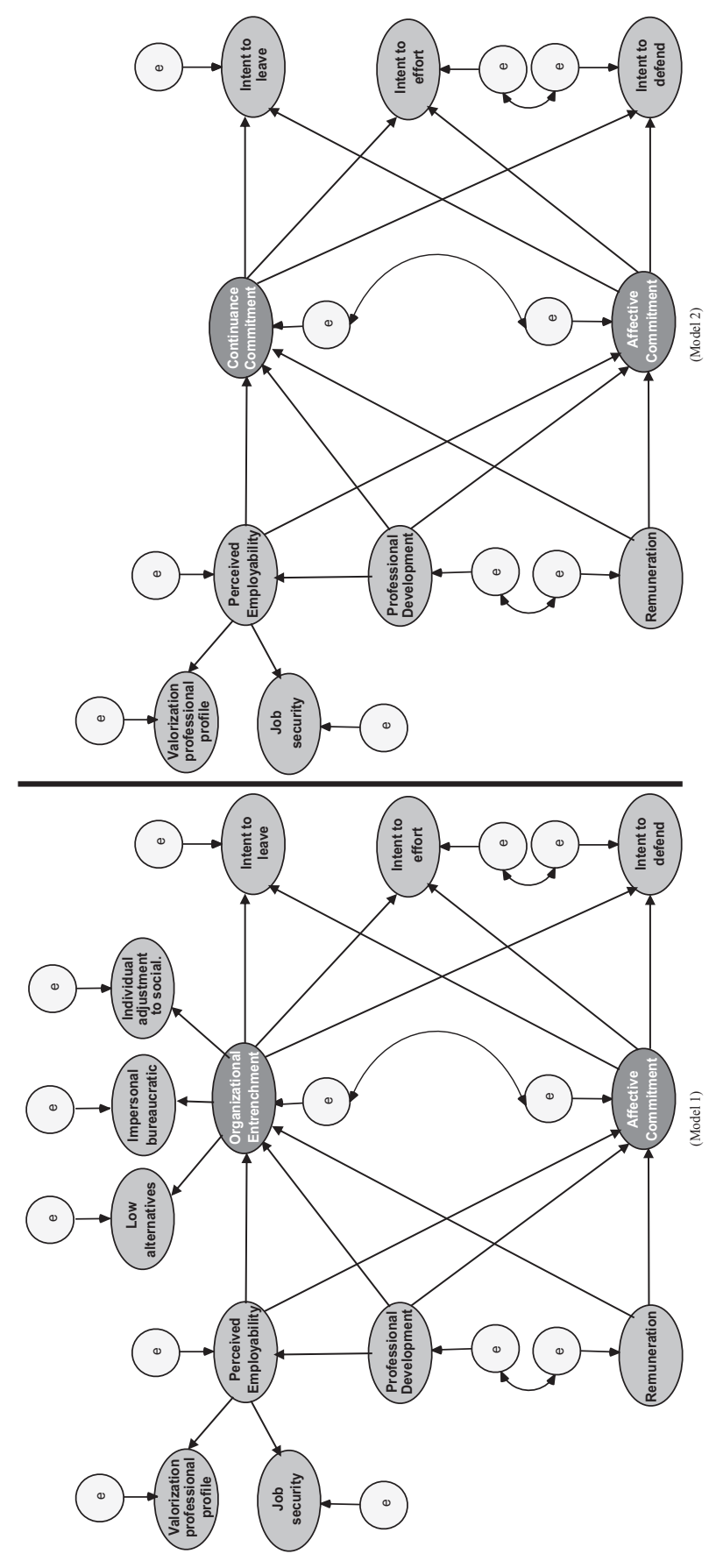


On the other hand, they claim that the investment in development may be interpreted as increased responsibility, or the employee may ignore that the increase in external employability is due in part to these investments. In this case, as the perception of external employability increases, the employee may extend the intention to leave the organization for other opportunities evaluated as qualitatively better than the current one. Based on this reflection, De Cuyper \& De Witte (2011) expected that the perception of internal employability would present a positive relationship with AC, as was indeed observed. They also expected that the perception of external employability would have a negative impact on commitment, although this hypothesis was only partially confirmed: when mediated by the perception of higher quality of external employability, the relationship between perceived employability and external $\mathrm{AC}$ was negative, but when evaluated directly, this relationship was positive.

One possible explanation for these results is that the perception of employability positively impacts on $\mathrm{AC}$ when an employee perceives positive prospects for his/her development in the organization. In this case, the worker stays, if that opportunity is evaluated as the best one, even if there is another available. Regarding the perception of external employability, the same way that higher quantity and quality of opportunities can lead the employee to leave the organization, a narrower external employability perception may cause the employee to stay because of a lack of alternatives, thus increasing the individual's instrumental bond, in this case, OE. Meyer \& Allen (1997) predicted that relationship when they said that the perception of available alternatives would impact negatively on CC. Thus, it is not the perception of greater external employability which necessarily reduces commitment, but the perception of lower employability which increases the entrenchment. This reflection leads to the first hypothesis:

H1. The perception of employability has a negative impact on $\mathrm{OE}$ and $\mathrm{CC}$, and a positive impact on $\mathrm{AC}$.

In this work, we assess employability using items constructed to measure the market value of the professional profile and job stability. Therefore, the dimensions of De Cuyper \& De Witte (2011) were not directly assessed but were considered by the items' content.

\subsection{Policies and personnel management practices}

Despite the advances in research on antecedents and consequences, in the $\mathrm{OC}$ literature there are proportionately less studies on the impact of human resources management practices on the bonds between the individual and the organization (Meyer \& Allen, 1997). This trend leads to increased speculation about which practices generate commitment and thus, as stated by Morrow (2011), to a policy framework used by organizations with few substantive strategies.

Meyer \& Allen (1997), Morrow (2011), Wright \& Kehoe (2008) emphasize the management of psychological bonds. An emphasis on AC is visible, since this is the type of commitment most desired by organizations. Thus there is concern toward identifying practices that encourage $\mathrm{AC}$ without necessarily increasing the $\mathrm{CC}$ of the worker. Still, there are no conclusive results about the impact of human resources management practices, nor is there any consensus about its effects on the types of bonds between the individual and the organization.

Morrow (2011) reviewed longitudinal research related to management of commitment and concluded that human resources management practices have a limited role in the development of bonds. One possible explanation for this is that personnel management practices are conditioned to how they are perceived by employees (Meyer \& Allen, 1997; Fiorito, Bozeman, Young \& Meurs, 2007; Wright \& Kehoe, 2008). Practices interpreted as 
REGE

29,1

amplifying the costs of leaving the organization will contribute to an increase in the instrumental bond, whereas practices interpreted as evidence of organizational support will tend to strengthen the emotional bond. Consider, for instance, training and development (T\&D) practices, since workers may perceive them as indicators of their valuation by the organization or as instruments for enhancing non-transferable skills and knowledge (Meyer \& Allen, 1997). These interpretations circulate between the poles of valuation versus accumulated costs, which are, respectively, predictors of $\mathrm{AC}$ and $\mathrm{CC}$.

Wright \& Kehoe (2008) argue that T\&D practices both increase the perception of employees that the organization values their current and future contributions, as well as increase their perceived employability. Consequently, these practices will have a positive impact on $\mathrm{AC}$ and present a null or negative relationship with $\mathrm{CC}$.

Scheible \& Bastos (2013) examined the impact of human resource management practices on $\mathrm{OC}$ and $\mathrm{OE}$. They noted that T\&D practices do not relate to $\mathrm{OE}$ but have positive relationships with AC. Furthermore, they strongly influence AC without potentiating OE. These findings and reflections led to the second hypothesis of this study:

H2. Professional development practices have a greater positive impact on AC than on CC and $\mathrm{OE}$.

Regarding remuneration practices, Wright \& Kehoe (2008) also predict variation in experiences and interpretations. Once compensation is evaluated positively, the worker may perceive a restriction on alternatives in the market that offer the same financial return. The employee may also feel grateful to the organization for a highly rated salary or perceive fairness in the compatibility between performance and financial reward (Fiorito, Bozeman, Young \& Meurs, 2007). The reviews conducted by Morrow (2011) point to the growth of $\mathrm{AC}$ due to compensation practices, as long as workers value greater individualism, autonomy or are heavily involved with projects currently in development (Workman \& Bommer, 2004).

Upon analyzing correlations between the types of bonds with the organization and compensation and benefits practices, Scheible \& Bastos (2013) found a positive relationship with $\mathrm{AC}$, and in lower intensity with $\mathrm{OE}$. Among the $\mathrm{OE}$ dimensions, the "impersonal bureaucratic arrangements" component showed higher correlation, being consistent with its definition. Despite the existing correlations with both types of bonds, when regression analyses were applied, the authors verified that compensation and benefits practices potentiated only OE.

The results of studies examining remuneration assume that a positive evaluation of this variable can strengthen both types of bonds, especially the instrumental type. Thus:

H3. Remuneration practices have a greater positive impact on $\mathrm{OE}$ and on $\mathrm{CC}$ than on $\mathrm{AC}$.

\subsection{Behavioral intentions}

Fishbein \& Ajzen (1975) proposed a distinction between attitudes and behavioral intentions. Until then, intentions were often considered as intrinsic to attitudes, though not discussed at the conceptual level. Operationally, the models saw constant failures when trying to relate beliefs, attitudes and behaviors.

In order to understand how attitudes can have impact on actions, Eagly \& Chaiken (1998) differentiated the attitude toward an object from the attitude toward $a$ behavior. Whereas the second is more specific and directly related to the behavior in question, the first is broader and related to a greater variety of behaviors, although it does not exert direct influence on them. Five predictors were defined for attitude toward a behavior: habits, attitude toward an object, and three classes of anticipated effects of this behavior (instrumental, normative and identityrelated). Regarding the results, the individual can perceive potential disadvantages arising 
from certain behaviors, which can be loss of benefits (instrumental), guilt (normative) or Commitment or impacts on the self-concept (identity).

Solinger, Olffen \& Roe (2008) evaluated how Meyer \& Allen's (1991) TCM adapts to this proposal. AC corresponds to the attitude toward an object (the organization), and CC represents the instrumental results also reflected by the notion of side bets. The normative component portrays normative results and self-concept, which can also generate disapproval and feelings of guilt. These instances, in addition to habits, influence each other and influence the attitude toward a behavior. In the model, the attitude toward the behavior and the effects on identity generate an intention that, as a habit, can lead to action.

Taking into account this adaptation, Solinger et al. (2008) concluded that normative and $\mathrm{CCs}$ are antecedents of attitudes toward a behavior or, more precisely, different classes of consequences imagined by the individual for the case of not staying employed. Thus, they considered it understandable that $\mathrm{AC}$ relates to different behaviors, such as permanence, performance, organizational citizenship behavior, among others already verified in empirical studies (Meyer, Stanley, Herscovitch \& Topolnytsky, 2002). An attitude toward a behavior is more restricted, since the resulting behavior (staying in the organization) is already specified. Following this argument, they justified the results found in studies on CC, since there are few variables with which it has significant relationships when compared to the associations found for AC.

Even though commitment was being treated primarily as an attitude, from early on, a strand of behavioral commitment is also present. Some examples are Becker's (1960) side bets theory, and the concept of commitment presented by Mowday, Porter \& Steers (1982), as being the general force of the individual's identification and involvement with the organization. There are three dimensions: belief and acceptance of organizational goals and values (attitudinal component); desire to make extra effort on behalf of the organization and desire to remain a member of the organization (behavioral components).

We have included in this study three types of behavioral intentions: intentions to defend the organization, to make extra effort at work (intentions to contribute) and intentions to leave the organization. Previous studies have provided support for the following hypotheses:

H4. AC has a positive impact on intentions to contribute (defense and extra effort), whereas $\mathrm{OE}$ and $\mathrm{CC}$ have a negative impact on these intentions;

H5. The three types of bonds generate similar negative impacts on the variable "intention to leave the organization."

\subsection{General hypothesis}

In addition to the parameters specified for the antecedents and consequences investigated, the parameters between $\mathrm{OE}$ and $\mathrm{AC}$ and between $\mathrm{CC}$ and $\mathrm{AC}$ were added to the models. This inclusion was based on preliminary analyses, which indicated significant relationships between $\mathrm{AC}$ and other types of bonds. A parameter between professional development and perception of employability, congruent with the theoretical discussion presented above, was also added.

Given the issues raised, the general hypothesis of this study is:

H6. $\mathrm{OE}$ and $\mathrm{CC}$ exhibit patterns of relationship similar to the variables of the model, which differ from the pattern established by AC.

\section{Method}

3.1 Data and sample

We conducted an extensive cross-sectional study, which covered a sample of 1,664 workers. After removing outliers, the database retained 1,648 respondents. As the inclusion criteria for 
REGE

29,1

participating in the research, it was only required that the respondent was over 18 years of age and working at the time of participation.

In order to facilitate data collection from distinct groups of workers, three strategies were used: (1) self-administered, printed questionnaires distributed to workers with a higher level of education, from organizations of different sizes and segments, covering $70.2 \%$ of the sample; (2) digital version of the questionnaire distributed by e-mail, also available through the link generated by Survey Monkey, which is a tool for construction of questionnaires on the Internet, accounting for 8.3\% of respondents; (3) Finally, interviews with workers having a lower level of education, supported by visual aids to enable better understanding of the questions, totaling $21.6 \%$ of the participants. All participants had access to the general objectives and informed consent of the research, including the guarantee of the confidentiality of responses and the possibility of discontinuing participation at any time.

Of the total participants, $61.1 \%$ lived in the Northeast, and $30.5 \%$ lived in the Southeast region of Brazil. The majority $(76.7 \%)$ worked in private companies, working mainly in services $(46.5 \%)$ and industry (11.6\%). Just over half of the participants were female $(57.1 \%)$, single $(50.8 \%)$ and under 35 years old $(64.5 \%)$. Regarding education, the majority had, at least, begun college studies (45.6\%). As to monthly income, $48.5 \%$ received up to five times the minimum wage (approximately US\$326.75). The data generally showed small deviations from normality.

\subsection{Measures}

The measures and their reliability indicators are described below. We used a six-point Likert scale for all the measures, ranging from 1 (strongly disagree) to 6 (strongly agree). Due to the lack of previous measures to assess some of the variables (e.g. "Human resources management practices" and "Perceived employability", some of the items were specified in this study. We have conducted exploratory and confirmatory analyzes before hypotheses testing. The alphas are also shown below.

3.2.1 Organizational entrenchment. We used the reduced version of the Rodrigues and Bastos OE measure (Rodrigues \& Bastos, 2012), with three dimensions: Individual adjustment to social positions (6 items)-Sample item: "If had to work at another company, I would be throwing away all the efforts I made to get where I am in this company" $(\alpha=0.78$, average inter-item correlation of 0.37 , and item-total correlations above 0.45$)$; Impersonal bureaucratic arrangements (6 items)-Sample item: "To leave this organization now would result in financial losses" ( $\alpha=0.76$, average inter-item correlation of 0.35 , and item-total correlations above 0.44); Low alternatives (6 items)-Sample item: "I think I would have few employment alternatives if I left this organization" ( $\alpha=0.75$, average inter-item correlation of 0.33 and item-total correlations above 0.41 );

3.2.2 Continuance commitment. We used the reduced version of the $\mathrm{CC}$ measure validated by Bastos, Pinho, Aguiar \& Menezes (2011) for the Brazilian context (5 items)-Sample item: "Leaving this organization now would require considerable personal sacrifices" $(\alpha=0.71$, average inter-item correlation of 0.34 and item-total correlations above 0.39 );

3.2.3 Affective commitment. We used the reduced version of the AC measure validated by Bastos et al. (2011) for the Brazilian context (7 items)-Sample item: "I think my values are very similar to the values defended by the organization where I work" ( $\alpha=0.86$, an average interitem correlation of 0.46 and item-total correlations above 0.58 ).

3.2.4 Perceived employability. We assessed the perception of employability using items constructed to measure two dimensions: Valorization of professional profile (5 items)-Sample item: "I feel that I have knowledge and skills important for the labor market" ( $\alpha=0.74$, average inter-item correlation of 0.37 and item-total correlations above 0.46 ); Job security 
(4 items)-Sample item: "I do not feel threatened to lose this job" ( $\alpha=0.75$, average inter-item Commitment or correlation of 0.42 and item-total correlations above 0.50 ).

3.2.5 Human resources management practices. We elaborated seven items for measuring two groups of perceived HRM practices: Professional development and career practices (4 items)-Sample item: "There are opportunities for career growth and professional progress in this organization" ( $\alpha=0.78$, average inter-item correlation of 0.47 and item-total correlations above 0.55); Remuneration practices (3 items)- Sample item: "Considering my professional qualifications, I receive adequate remuneration" ( $\alpha=0.79$, average inter-item correlation of 0.55 and item-total correlations above 0,61 ).

3.2.6 Behavioral intentions. Adapted version of the measures validated by Menezes \& Bastos (2010). Intentions to leave the organization, 4 items $(\alpha=0.78$, average inter-item correlation of 0.47, item-total correlations above 0.58). Sample item: "I would accept the proposal for another job, if it offered the opportunity for growth within the new company"; Intentions to contribute, 9 items divided into two sub-dimensions: Intention to defend, 5 items $(\alpha=0.85$, average inter-item correlation of 0.53 and item-total correlations above 0.63 ). Sample item: "I would defend the organization regarding criticisms from people who are not part of it"; Intentions toward extra effort, 4 items $(\alpha=0.77$, average inter-item correlation of 0.45 and item-total correlations above 0.50 )-"I would broaden my workload if it was important for improving the performance of the organization."

\section{Results}

First, we used Pearson's correlation analysis to examine the relationships between the variables. Then we used structural equation modeling for testing measurement and structural models. As the method of estimation, we used maximum likelihood (ML). Hair, Anderson, Tatham \& Black (2005) also suggest that the cutoff of index values takes into account the complexity of the model and the sample size. Thus, the cutoff expected for evaluated fit indices in this study follows the guidelines for models with more than 30 observable variables and more than 250 sample cases. We used normed fit index (NFI) and comparative fit index (CFI), Goodness of Fit Index (GFI) and Adjusted Goodness of Fit Index (AGFI), Resting metabolic rate (RMR), Root mean square error of approximation (RMSEA) and $\chi^{2}$, which can display significant $p$-values for the size of our sample. Parsimony goodness-of-fit index (PGFI) was analyzed for comparison of structural models.

\subsection{Descriptive statistics and correlations between variables}

Table 1 shows descriptive statistics and Pearson correlations for all variables. All the organizational linkages were correlated with one another, but the relationship between $\mathrm{OE}$ and $\mathrm{CC}$ was stronger than those existing between $\mathrm{AC}$ and these two bonds. High and positive correlations between $\mathrm{AC}$ and the variables investigated were found. The exceptions were for intent to leave the organization, with which $\mathrm{AC}$ presented a moderate and negative relationship, and the perception of low alternatives, with which it had no significant relationship. $\mathrm{OE}$ and $\mathrm{CC}$ showed weak or moderate relationships with these variables.

Regarding the perception of employability, OE showed a weak and opposite relationship to that shown by AC. CC was not significantly related to this variable. When analyzing the dimensions of $\mathrm{OE}$, a strong negative relationship of low alternatives with perceived employability was noticed.

AC showed strong and positive relationships with the human resources management practices investigated. Relationships between $\mathrm{CC}$ and $\mathrm{OE}$ with these practices, although weaker, were also positive. The individual adjustment to social positions dimension stood out for demonstrating a moderate relationship with professional development. Low 
REGE

29,1

28

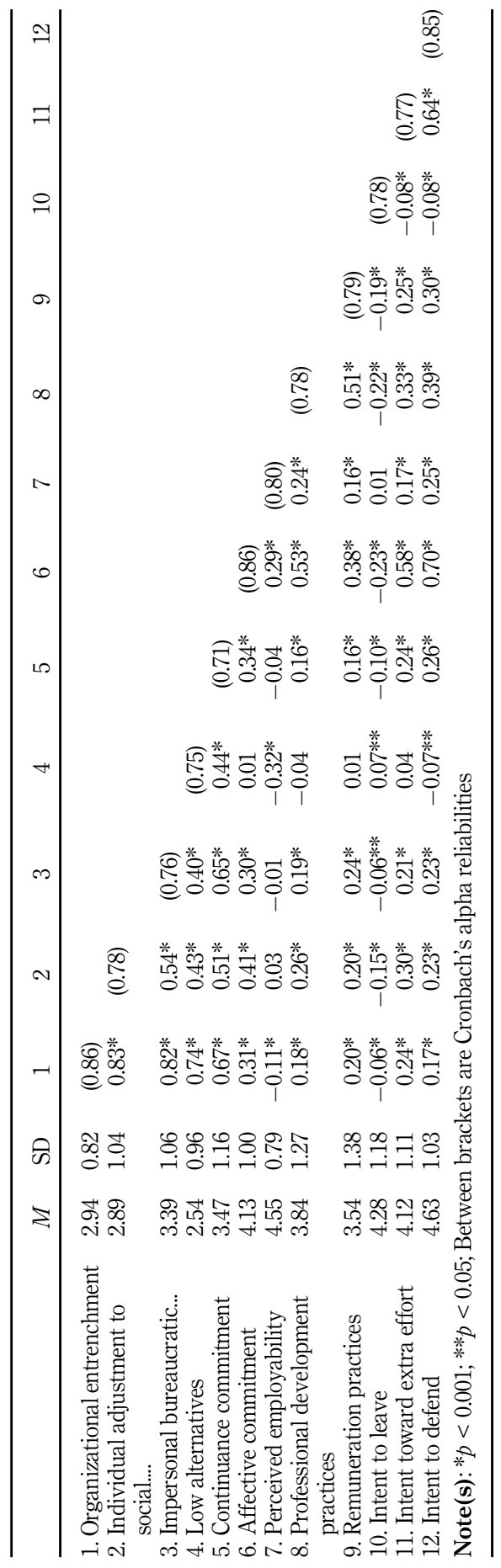

Table 1.

Descriptive statistics and Pearson correlations for all variables 
alternatives, in turn, stood out by not showing a significant relationship with any of the practices.

The three types of bonds studied correlated positively with the intention toward extra effort and defense. AC showed strong positive relationships. $\mathrm{CC}$ and $\mathrm{OE}$ showed moderate or weak positive relationships. There were weak correlations between the low alternatives and intention to contribute dimensions. In the case of intention to defend, correlation was in the direction opposite to the others.

Negative relationships were identified between behavioral intent to leave the organization and the three types of bonds studied, although in the case of $\mathrm{OE}$ and $\mathrm{CC}$ they were weak, and in the case of the $\mathrm{AC}$, they were moderate. Regarding the dimensions of $\mathrm{OE}$, only low alternatives presented a positive relationship, albeit weak, with intent to leave the organization.

The results shown in Table 1 also allow us to add a relevant note regarding the characteristics of the sample studied. Generally, there are no participants with high OE or low $\mathrm{AC}$, considering the averages and standard deviations found.

\subsection{Measurement models}

Table 2 presents the fit indices of the measurement models used in the specification of the structural model, considering the total sample.

The models of perceived employability and management practices presented, in an initial test, good fit indices. Meanwhile, the inspection of modification indices pointed out the possibility of adding parameters between the errors of two variables, job security (subdimension of perceived employability) and professional development and career practices. The modifications were identified and re-evaluated from the cross-validation with subsamples of all respondents, in order to avoid a super adjustment of the models to the sample.

\subsection{Structural models}

Table 3 presents the fit indices of the models. Model 1 tested the relationship between $\mathrm{AC}$ and $\mathrm{OE}$ with antecedent and consequent variables. Model 2 tested the relationships between $\mathrm{AC}$ and $\mathrm{CC}$ with the same variables.

\begin{tabular}{lrrrlllll}
\hline & $\chi^{2}$ & GL & RMR & GFI & AGFI & RMSEA & NFI & CFI \\
\hline Affective commitment & $111.19 * *$ & 14 & 0.06 & 0.98 & 0.96 & 0.06 & 0.97 & 0.98 \\
Continuance commitment & $13.417^{*}$ & 5 & 0.04 & 1.0 & 0.99 & 0.03 & 0.99 & 0.99 \\
Organizational entrenchment & $586.37 *$ & 131 & 0.10 & 0.96 & 0.95 & 0.05 & 0.92 & 0.94 \\
Perceived employability & $180.01^{* *}$ & 25 & 0.06 & 0.98 & 0.96 & 0.06 & 0.95 & 0.96 \\
Human resources management practices & $79.13^{* *}$ & 12 & 0.07 & 0.99 & 0.97 & 0.06 & 0.98 & 0.98 \\
Intent to leave & 3.53 & 2 & 0.02 & 1.0 & 1.0 & 0.02 & 1.0 & 1.0 \\
Intent to contribute & $215.68^{* *}$ & 26 & 0.06 & 0.97 & 0.95 & 0.07 & 0.96 & 0.97
\end{tabular}

$\operatorname{Note}(\mathbf{s}): * p<0.001 ; * * p<0.05$
Commitment or entrenchment in the TCM model?

\section{1}


REGE 29,1

Model 1 was specified and initially tested with 132 parameters. Post hoc modification indices indicated a significant improvement in the model fit with the addition of a parameter between the latent variables "perceived employability" and "low alternatives" (Modification indices $=265.20$; Magnitude of change $=-0,761$ ). Considering the approximation of significance of these variables, in addition to the high correlation coefficient found previously $(\mathrm{r}=-0.31)$, we proceeded with the specification of this new parameter.

After respecification, both models showed good fit indices, except for the NFI for Model 1. Hair, Anderson, Tatham \& Black (2005) warn that the NFI penalizes more complex models. The results of the other indices indicate good model fit. Figures 3 and 4 show, respectively, the standardized coefficients of models 1 and 2 . AC was positively related with $\mathrm{OE}(\varphi=0.44 ; p<0.001)$ and with $\mathrm{CC}(\varphi=0.43 ; p<0.001)$. Consistent with the previously discussed literature (De Cuyper \& De Witte, 2011), the positive impact of professional development practices on perceived employability was observed in the two models $\left(\gamma_{M 1}=0.34 ; \gamma_{M 2}=0.30 ; p<0.001\right)$. The parameter added to model 1 indicated a strong negative impact of perceived employability on the low alternatives dimension of $\mathrm{OE}$ $(\gamma=-0.51 ; p<0.001)$.

Perceived employability showed moderate and positive relationships with $\mathrm{AC}\left(\gamma_{M 1}=0.23\right.$; $\left.\gamma_{M 2}=0.21 ; p<0.001\right)$, and negative relationships, though weak, with $\mathrm{OE}(\gamma=-0.15$; $p<0.001)$ and with CC $(\gamma=-0.15 ; p<0.001)$. Therefore, Hypothesis 1 was confirmed.

Practices for professional development showed a greater positive impact on AC $\left(\gamma_{M 1}=0.47 ; \gamma_{M 2}=0.48 ; p<0.001\right)$ than on $\mathrm{OE}(\gamma=0.29 ; p<0.001)$ and on $\mathrm{CC}(\gamma=0.17$; $p<0.001)$, as predicted by Hypothesis 2 . Remuneration practices also showed positive associations with $\mathrm{AC}\left(\gamma_{M 1}=0.11 ; \gamma_{M 2}=0.11 ; p<0.001\right)$, $\mathrm{OE}(\gamma=0.16 ; p<0.001)$ and $\mathrm{CC}$ $(\gamma=0.12 ; p<0.001)$. Although, in fact, the coefficients were slightly higher for $\mathrm{OE}$ and $\mathrm{CC}$ than for AC, Hypothesis 3 was partially confirmed, since the differences were not significant.

As predicted, AC had a positive impact on intent to defend $\left(\gamma_{M 1}=0.90 ; \gamma_{M 2}=0.84\right.$; $p<0.001)$ and on intent to extra effort $\left(\gamma_{M 1}=0.70 ; \gamma_{M 2}=0.70 ; p<0.001\right)$. OE had a weak negative association with the intent to defend $(\gamma=-0.14 ; p<0.001)$, and CC did not show significant relationship with this variable. Intent to extra effort, in turn, was not significantly impacted by $\mathrm{OE}$ and $\mathrm{CC}$. Thus, Hypothesis 4 was partially confirmed.

$\mathrm{AC}$ generated moderate and negative impact on intent to leave the organization $\left(\gamma_{M 1}=-0.22 ; \gamma_{M 2}=-0.23 ; p<0.001\right)$. The same was not observed for the other types of bonds, which showed no significant relationship with this variable. Thus, Hypothesis 5 was partially confirmed.

Although the results found have not confirmed all the hypotheses of the study, they indicate the same pattern of relationships established by $\mathrm{OE}$ and $\mathrm{CC}$, which clearly differs from the pattern of relationships of AC. Thus, Hypothesis 6 was confirmed in this study.

\section{Discussion}

The confirmation of Hypothesis 6 shows that there are two types of bonds which relate differently to the variables evaluated, one type being affective and a second type of an instrumental nature. These results answer the questions posed earlier in this article about the validity of measures of $\mathrm{OE}$ and $\mathrm{CC}$. In fact, both measures assess the same construct, which differs in the nomological network of AC. Therefore, it is not valid to say that the measure of $\mathrm{CC}$ measures commitment when it is actually measuring another construct. Conversely, if the same scale was used for the measurement of $\mathrm{OE}$, it is correct to say that the measure is valid, considering the theoretical and empirical aspects observed.

The best fit of model 2 compared to model 1 confirms the trends in structural equation modeling analyses to provide the best adjustments for more parsimonious models, or with a smaller number of variables and parameters (Ullman, 2007). Both proved to satisfactorily 


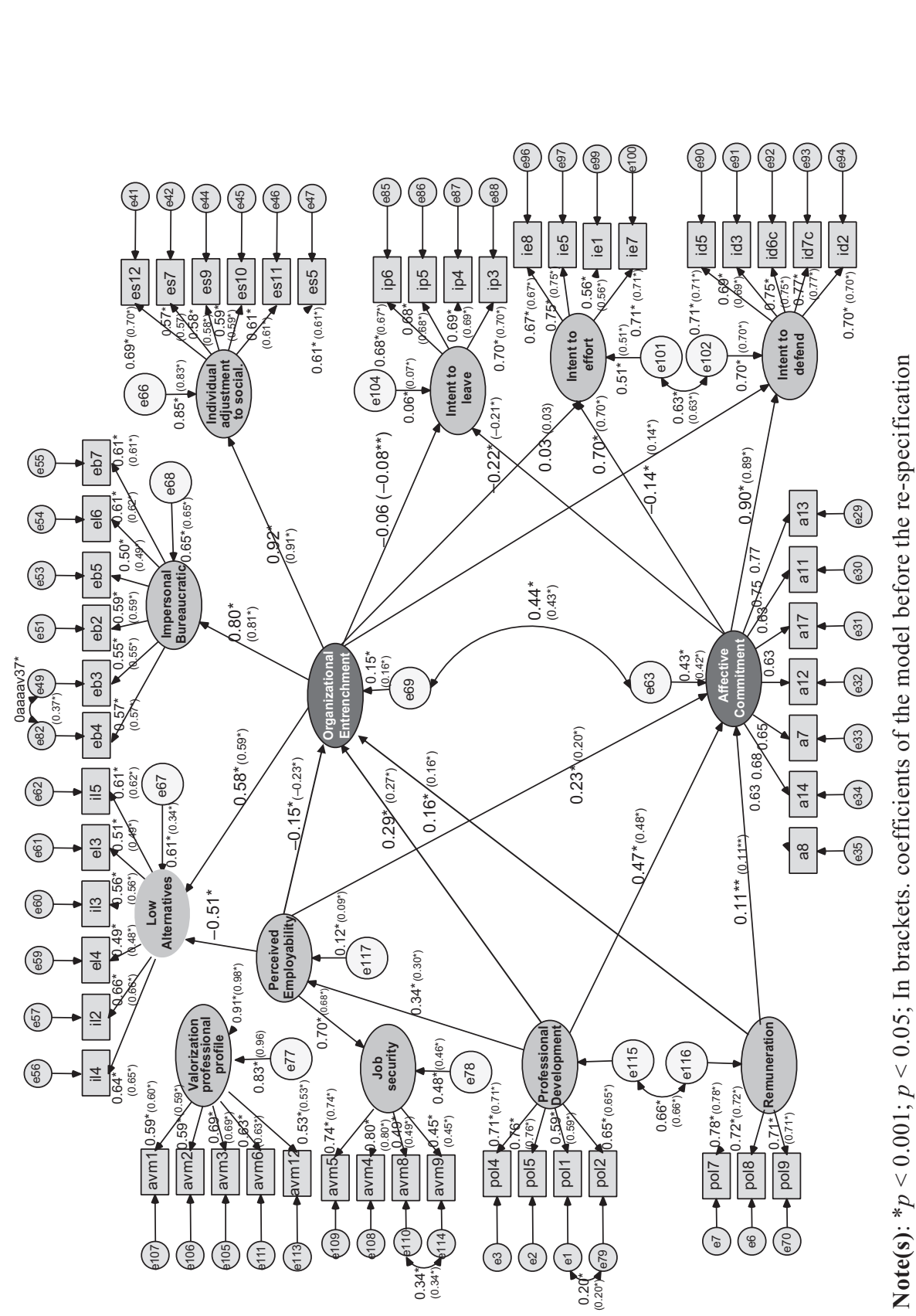

Commitment or entrenchment in the TCM model?

Figure 3.

Standardized coefficients of model 1 
REGE

29,1

32

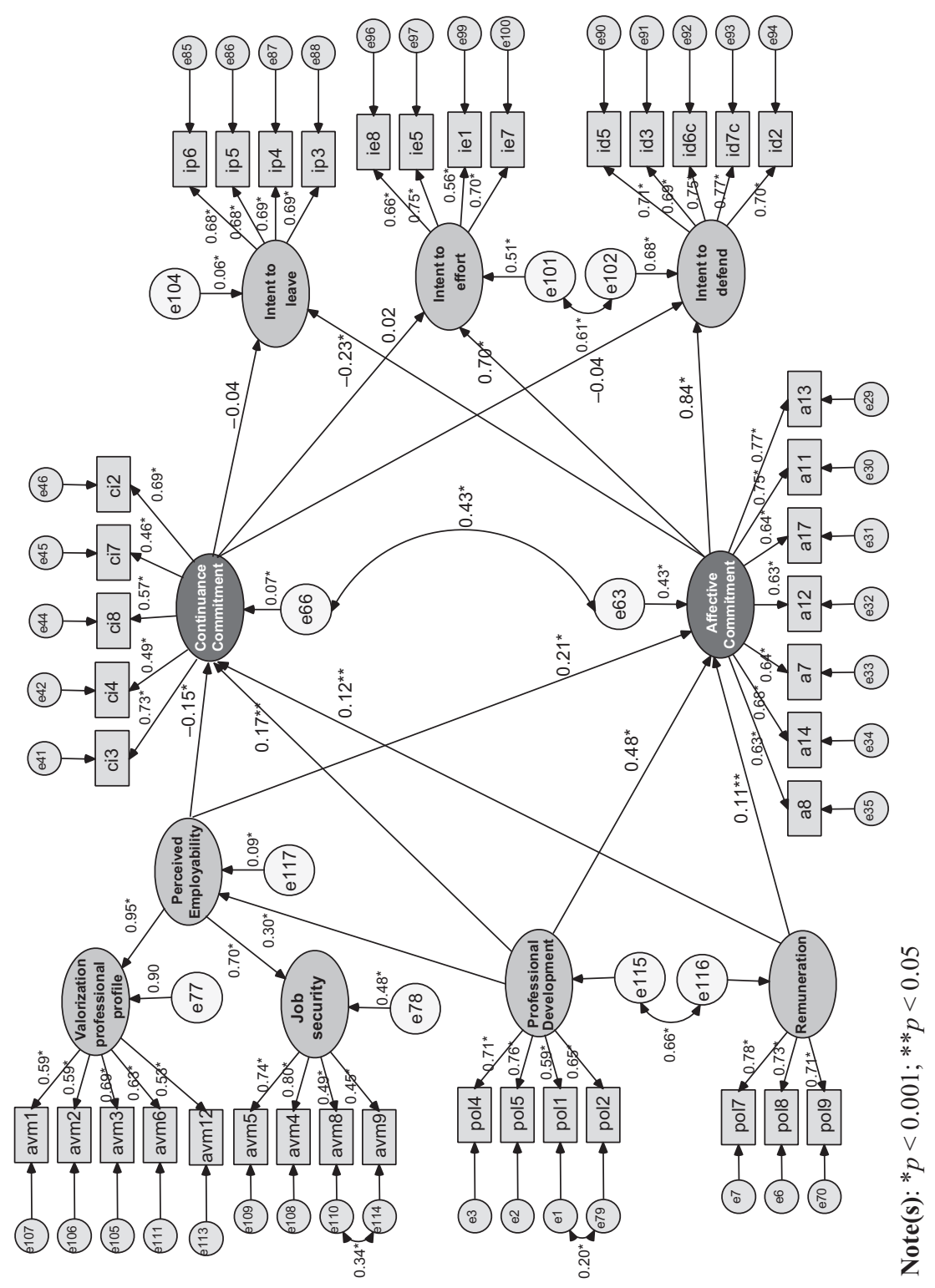

Figure 4.

Standardized

coefficients of model 2 
explain the variance of the data matrix from the sample, as observed by the values of the GFI and AGFI indices. Both are well suited to the data matrix, as indicated by the results of RMSEA and RMR, which also indicate an acceptable residual charge. The $\chi^{2}$, as expected, given the characteristics of the sample, was significant. The comparative fit indices (NFI and CFI) indicate that model 2 was satisfactorily specified, with regard to other possible alternatives for the variables that comprise it. In the case of model 1, the CFI confirmed the same result, even though the NFI, which tends to be lower for more complex models, indicates the possibility of a better alternative.

It is possible, in the case of model 1, that the stronger relationship between $\mathrm{AC}$ and the sub-dimension "individual adjustment to social positions" generates residuals, since a direct parameter between these variables was not specified. Although there is a positive relationship between $\mathrm{AC}$ and $\mathrm{OE}$, similar to that established between $\mathrm{AC}$ and $\mathrm{CC}$, the individual adjustments to social position dimension includes a process that may involve identification, also present in the process of AC. This possibility is consistent with the theoretical model of OE (Rodrigues \& Bastos, 2011a), which admits the possibility of an employee being simultaneously entrenched and committed to the organization.

The strong negative impact of perceived employability on low alternatives brings into focus the role of this dimension in the structure of $\mathrm{OE}$, as pointed out by Rodrigues \& Bastos (2012). On one hand, the perception of low alternatives is a fundamental part of the process of OE. On the other hand, the comparison with perceived employability clearly indicates an approximation with its content, both in concept and in the operationalization of items. The low alternatives dimension semantically approaches the valorization of professional profile sub-dimension, as if it were a negative measure of this sub-dimension.

Additionally, correlation analyses indicated low or zero significance relationships between low alternatives and the antecedent and consequence variables investigated, with the exception of perceived employability. Many of these relationships differ from those established by the dimensions individual adjustment to social positions and impersonal bureaucratic arrangements. Rodrigues \& Bastos (2012) proceeded with the content validation of the $\mathrm{OE}$ scale and discussed the cyclical role of the concept of low alternatives, which can be both intrinsically and extrinsically perceived. However, the notion of intrinsic limitations is not present among the items measuring individual adjustment to social positions and impersonal bureaucratic arrangements, which might have caused the detachment of the dimension low alternatives dimension.

The results to date indicate that the measure of $\mathrm{CC}$ does not address the full range of meaning of the concept of $\mathrm{OE}$. The measure constructed and validated by Rodrigues \& Bastos (2012) is the one that best accesses the theoretical framework of this type of bond. Its wider extent explains why, in general, the measure of $\mathrm{OE}$ presented correlation and regression coefficients slightly higher than those observed for $\mathrm{CC}$. $\mathrm{OE}$ also showed greater variance explained by the antecedents of $\mathrm{CC}$.

These results certainly reflect the incorporation of content via the conceptual structure of $\mathrm{OE}$, which is not included in the scale of $\mathrm{CC}$. One indication of this effect concerns the moderate correlations of human resources management practices with the individual adjustment to social positions dimension, and, to a lesser degree, with the impersonal bureaucratic arrangements dimension. This, in turn, is the dimension that incorporates the content covered by the measure of $\mathrm{CC}$. Given these results and confirmation that $\mathrm{OE}$ and $\mathrm{CC}$ represent the same bond, it is considered appropriate to designate this type of bond simply as $\mathrm{OE}$.

Confirmations of Hypotheses 1 and 2 are consistent with previous discussions of the work of De Cuyper \& De Witte (2011), and Wright \& Kehoe (2008): practices for professional and career development generate positive impacts on $\mathrm{AC}$, since they are certainly interpreted as indicative of professional valuation and do expand employability prospects, generating the 
REGE

29,1

\section{4}

desire to give back to the organization. However, when the professionals develop knowledge and skills focused strictly on their working organization, they tend to feel more trapped. Despite this moderate impact of professional development practices on $\mathrm{OE}$, when mediated by perceived employability, its effect is negative. As discussed in the theoretical model of $\mathrm{OE}$, the perception of alternatives in the labor market tends to reduce the need to stay in the organization.

The partial confirmation of Hypotheses 3, 4 and 5 reflects the greater knowledge about the behavior of $\mathrm{AC}$ than about $\mathrm{OE}$, which is a construct in development. Moreover, the restriction of the variability of the types of bonds in the sample studied should also be considered as a possible reason for these findings.

Morrow (2011) states that human resources management practices usually have limited effects on AC, since they are conditioned to the individual's perception. In the case of remuneration practices, it is speculated that there is a tendency for workers to evaluate them more negatively than positively. Therefore, the impact on the types of bonds established by the employees with the organization tends to be lower, since this depends on the evaluation made by the individuals themselves.

The high correlation and regression coefficients observed between $\mathrm{AC}$ and intent to contribute indicate a possible overlap. This result is consistent with the study of Menezes \& Bastos (2010), who tested behavioral intentions toward extra effort and defense as part of behavioral commitment. In this study, the authors also noted that the intentions to stay do not make up the factor structure of behavioral commitment, thus assuming the role of a possible consequent. The moderate correlation and regression coefficients in this study corroborate these findings.

The weak relationships existing between $\mathrm{OE}$ and intentions to contribute are explained by their theoretical model, according to which the state of $\mathrm{OE}$ is generated by the set of accumulated costs and the difficulty in identifying alternatives to reduce these costs. Therefore, it is understandable that this bond has zero or negative impact on intentions to contribute to the organization. On the other hand, it was expected that OE would have a significant impact on the intentions to leave/stay, which should be addressed in more detail in future studies using other research models.

The fact that this is a cross-sectional study sets a limitation on the results, for not allowing greater understanding of the dynamics and the causal direction of relationships. Additionally, it follows the trend of studies in the organizational behavior field of utilizing self-reported data, which results in problems related to perceptual bias (Morrow, 2011).

The relationships found between the perception of low alternatives and perceived employability reinforce the need to revise the measure of $\mathrm{OE}$, with the inclusion of items that operationalize the notion of intrinsic limitation, present in the theoretical definition of $\mathrm{OE}$. That done, an evaluation of the relevance of the concept of extrinsic limitations in the construct is recommended, since it overlaps with the perceived employability dimension.

\section{Conclusions}

The whole construction of relevant scientific knowledge depends upon the validation of the constructs. In this paper, we analyzed the convergent validity of $\mathrm{OE}$ and $\mathrm{CC}$ and their discriminant validity in relation to AC. At this point of the research agenda on organizational bonds, the results represent evidence of overlap between $\mathrm{OE}$ and $\mathrm{CC}$. Therefore, after analyzing and interpreting the data, we conclude that $\mathrm{CC}$ should not be part of commitment but part of $\mathrm{OE}$.

It is important that further research be conducted with the application of procedural methodologies, such as longitudinal and trans-sequential studies, in addition to alternatives that encompass qualitative methodologies for data collection and analysis. In this sense, the 
need is highlighted for researchers to also consider the individual's life stage, to approach the complex web of relationships that, inside or outside the organizational context, impact on the bonds established by workers. It is also suggested that the development of a measure that assesses the state or the feeling of being entrenched, since the current measure assesses the process of entrenchment. Finally, the importance of investigating a set of antecedent and consequent variables is highlighted, especially in relation to organizational entrenchment, whose studies are still initial. Some examples are variables related to work experiences (autonomy and challenge at work, organizational support, leadership characteristics, perception of justice and reciprocity), accumulated cost variables (salary, investments made, transferability of skills), well-being variables (stress, work-family conflict), withdrawal behaviors (turnover, voluntary absence) and productive behaviors (performance, organizational citizenship).

We expect that these findings add a higher precision to the research on commitment, reinforcing its unidimensional approach and also contributing to the validity of the measures. Given these results and evidence that $\mathrm{OE}$ and $\mathrm{CC}$ represent the same bond, we consider appropriate to designate this type of bond simply as OE.

The results of this study represent a further argument in favor of prioritizing the affective dimension in research and in management of OC. If the heuristic meaning of commitment connects to dedication and willingness, entrenchment is expressed by necessary permanence. In this sense, the practical implications of this study regard a greater clarification on which behaviors are expected from either committed and entrenched workers, and which drivers may lead to each of these bonds. Therefore, a better understanding of the phenomenon contributes to the training of managers and to the design of organizational policies and practices. Among societal impacts, the clarity of bonds also allows its application to different contexts beyond business organizations, as a step to reach better understanding of commitment and entrenchment in different settings, economical and national realities.

\section{References}

Allen, N.J. (2016). Commitment as a multidimensional construct. Handbook of Employee Commitment. Northampton: Edgard Elgar Publishing, 1, 28-42.

Bastos, A.V.B., Pinho, A.P.M., Aguiar, C.V.N., \& Menezes, I.G. (2011). Comprometimento organizacional: aprimoramento e evidências de validade do modelo tridimensional de Meyer e allen no contexto brasileiro. In Zanelli, J.C., Silva, N., \& Tolfo, S.R. (Eds), Processos psicossociais nas organizações e no trabalho. São Paulo: Casa do Psicólogo, 145-160.

Becker, H.S. (1960). Notes on the concept of commitment. The American Journal of Sociology, 66, 32-40.

Blau, G. (2001a). On assessing the construct validity of two multidimensional constructs: Occupational commitment and occupational entrenchment. Human Resource Management Review, 11, 279-298.

Blau, G. (2001b). Testing the discriminant validity of occupational entrenchment. Journal of Occupational and Organizational Psychology, 74, 85-93.

Blau, G. (2009). Can a four-dimensional model of occupational commitment help to explain intent to leave one's occupation?. Career Development International, 14(2), 116-132.

Blau, G., \& Holladay, E.B. (2006). Testing the discriminant validity of a four-dimensional occupational commitment measure. Journal of Occupational and Organizational Psychology, 79, 691-704.

Carson, K.D., Carson, P.P., \& Bedeian, A.G. (1995). Development and construct validation of a career entrenchment measure. Journal of Occupational and Organizational Psychology, 68, 301-320. 
REGE 29,1

Cooper-Hakim, A., \& Viswesvaran, C. (2005). The construct of work commitment: Testing an integrative framework. Psychological Bulletin, 131(2), 241-259.

De Cuyper, N., \& De Witte, H. (2011). The management paradox: self-rated employability and organizational commitment and performance. Personnel Review, 40(2), 152-172.

Eagly, A.H., \& Chaiken, S. (1998). Attitude structure and function. In Gilbert, D.T. Fiske, S.T., \& Lindzey, G. (Eds), The handbook of social psychology. New York: McGraw-Hill, 1, 269-322.

Fiorito, J., Bozeman, D.P., Young, A., \& Meurs, J.A. (2007). Organizational commitment, human resource practices, and organizational characteristics. Journal of Managerial Issues, 19(2), $186-207$.

Fishbein, M., \& Ajzen, I. (1975). Belief, Attitude, Intention, and Behavior: An Introduction to Theory and Research. MA: Addison-Wesley.

Hair, J.F. Jr., Anderson, R.E., Tatham, R.L., \& Black, W.C. (2005). Análise multivariada de dados. Porto Alegre: Bookman.

Jaros, S.J. (1997). An assessment of Meyer and Allen“s (1991) three-component model of organizational commitment and turnover intentions. Journal of Vocational Behavior, 51, 319-337.

Klein, H. J., \& Park, H.M. (2016). Commitment as a unidimensional construct. In Meyer, J.P. (Ed.), Handbook of Employee Commitment. Northampton: Edgard Elgar Publishing, 1, 15-27.

Klein, H.J., Molloy, J.C., \& Brinsfield, C.T. (2012). Reconceptualizing workplace commitment to redress a stretched construct: Revisiting assumptions and removing confounds. Academy of Management Review, 37(1), 130-151.

Klein, H.J., Cooper, J.C., Molloy, J.C., \& Swanson, J.A. (2014). The assessment of commitment: Advantages of a unidimensional, target-free approach. Journal of Applied Psychology, 99(2), 222-238.

Ko, J.W., Price, J.L., \& Mueller, C.W. (1997). Assessment of Meyer and Allen's three-component model of organizational commitment in South Korea. Journal of Applied Psychology, 82, 961-973.

McGee, G.W., \& Ford, R.C. (1987). Two (or more?) dimensions of organizational commitment: Reexamination of the affective and continuance commitment scales. Journal of Applied Psychology, 72(4), 638-642.

Menezes, I.G., \& Bastos, A.V.B. (2010). Conception, development, and validation of behavioral intentions of organizational commitment scale (BIOCS). Avaliação Psicológica, 9(1), 119-127.

Meyer, J.P. (2016). Employee commitment: An introduction and roadmap. Handbook of Employee Commitment. Northampton: Edgard Elgar Publishing, 1, 3-14.

Meyer, J.P., \& Allen, N.J. (1991). A three-component conceptualization of organizational commitment. Human Resource Management Review, 1(1), 61-89.

Meyer, J.P., \& Allen, N.J. (1997). Commitment in the workplace: Theory, research and application. CaliforniaThousand Oaks: SAGE Publications.

Meyer, J.P., \& Herscovitch, L. (2001). Commitment in the workplace: Toward a general model. Human Resource Management Review, 11, 299-326.

Meyer, J. P., Allen, N.J., \& Smith, C.A. (1993). Commitment to organizations and occupations: Extension and test of a three-component conceptualization. Journal of Applied Psychology, 78(4), 538-551.

Meyer, J.P., Stanley, J.D., Herscovitch, L., \& Topolnytsky, L. (2002). Affective, continuance, and normative commitment to the organization: A meta-analysis of antecedents, correlates, and consequences. Journal of Vocational Behavior, 61, 20-52.

Milhome, J.C., Rowe, D.E.O., \& Santos, M.G.D. (2018). Existem Relações entre Qualidade de Vida no Trabalho, Comprometimento Organizacional e Entrincheiramento Organizacional?. Contextus Rev. Contemporânea de Economia e Gestão, 16(3), 232-252.

Morrow, P.C. (2011). Managing organizational commitment: Insights from longitudinal research. Jounal of Vocational Behavior, 79(1), 18-35. 
Mowday, R.T., Porter, L.W., \& Steers, R.M. (1982). Employee-Organization Linkages: The Psychology of Commitment or Commitment, Absenteeism, and Turnover. New York: Academic Press.

Osigweh, C.A.B. (1989). Concept fallibility in organizational science. Academy of Management Review, 14(4), 579-594.

Rodrigues, A.C.A., \& Bastos, A.V.B. (2010). Conceptual and empirical problems in organizational entrenchment in the TCM model? commitment research: A critical analysis of J. Meyer and N. Allen three-component model. Revista Psicologia Organizações e Trabalho, 10(2), 129-144.

Rodrigues, A.C.A., \& Bastos, A.V.B. (2011a). Entrincheiramento organizacional: Proposta de um novo vínculo indivíduo-organização. In Zanelli, J.C., Silva, N., \& Tolfo, S.R. (Eds.), Processos psicossociais nas organizações e no trabalho: 161-178. São Paulo: Casa do Psicólogo.

Rodrigues, A.C.A., \& Bastos, A.V.B. (2011b). Do comprometimento de continuação ao entrincheiramento organizacional: Evidências de sobreposição entre os construtos. Paper Presented at the Annual Meeting of ANPAD, Rio de Janeiro.

Rodrigues, A.C.A., \& Bastos, A.V.B. (2012). Organizational entrenchment: Scale development and validation. Psicol. Reflex. Crit., 25(4), 688-700.

Rodrigues, A.C.de A., \& Carvalho-Freitas, M.N.de. (2016). Theoretical fragmentation: Origins and repercussions in work and organizational Psychology. Revista Psicologia : Organizações e Trabalho, 16(4), 310-315, doi: 10.17652/rpot/2016.4.12630.

Rodrigues, A.C.A., Bastos, A.V.B., \& Moscon, D.C.B. (2019). Delimiting the concept of organizational commitment: Empirical evidence of the overlap between the entrenchment and the continuance mindset. Revista Organizações \& Sociedade (O\&S), 26(89), 338-358.

Rothwell, A., \& Arnold, J. (2007). Self-perceived employability: Development and validation of a scale. Personnel Review, 36(1), 23-41.

Scheible, A.C.F., \& Bastos, A.V.B. (2013). An examination of human resource management practices' influence on organizational commitment and entrenchment. Brazilian Administration Review, 10(1), 57-76.

Scheible, A.C.F., Bastos, A.V.B., \& Rodrigues, A.C.A. (2013). Career commitment and entrenchment: Should we integrate or rebuild these constructs? An exploration of their relationships with performance. Revista de Administração, 48, 530-543.

Sethi, V., \& King, R. (1998). The multidimensional nature of organizational commitment. Journal of Information Technology Management, 9(1), 13-26.

Silva, R.C.D., Tomazzoni, G.C., \& Costa, V.M.F. (2018). Comprometimento e Entrincheiramento Organizacionais: Uma Análise Comparativa com duas Instituições de Ensino Superior. GESTÃO.Org - Revista Eletrônica de Gestão Organizacional, 16(1), 57-68.

Solinger, O.N., Olffen, W., \& Roe, R.A. (2008). Beyond the three-component model of organizational commitment. Journal of Applied Psychology, 93(1), 70-83.

Souza, G.C.de, Aguiar, C.V.N., \& Carneiro, L.L. (2018). A influência dos vínculos com a organização sobre o bem-estar subjetivo do trabalhador. Revista Psicologia Organizações e Trabalho, 18(4), 460-467.

Ullman, J.B. (2007). Structural equation modeling. In Tabachnick, B.G., \& Fidell, L.S. (Eds), Using Multivariate Statistics. EUA: Pearson Education.

Workman, M., \& Bommer, W. (2004). Redesigning computer call center work: a longitudinal field experiment. Journal of Organizational Behavior, 25(3): 317-337.

Wright, P.M., \& Kehoe, R.R. (2008). Human resource practices and organizational commitment: a deeper examination. Asia Pacific Journal of Human Resources, 46(1), 6-20.

\section{Further reading}

Cronbach, L.J., \& Meehl, P.E. (1955). Construct validity in psychological tests. Psychological Bulletin, $52,281-302$. 
REGE

29,1

\section{About the authors}

Ana Carolina de Aguiar Rodrigues holds a $\mathrm{PhD}$ in psychology from the Federal University of Bahia (UFBA), graduated in administration from the State University of Bahia (UNEB). She is a $\mathrm{PhD}$ professor at the School of Economics, Administration and Accounting, University of São Paulo. She coordinates the People and Work in Different Contexts (GEPeT) research group. She was a visiting researcher at Sabanci University (Turkey), at Ohio State University (USA), and Université Paris 8 (France). She is currently the president of the International Cooperation Coordination of FEA-USP.

Antonio Virgílio Bittencourt Bastos holds a bachelor's degree in psychology from the Federal University of Bahia (1976), master's degree in education from the Federal University of Bahia (1982) and $\mathrm{PhD}$ in psychology from the University of Brasilia (1994), with concentration in Organizational and Work Psychology. He is currently a full professor of Social Psychology of Organizations at the Institute of Psychology, Universidade Federal da Bahia and also a CNPq I-A researcher, working mainly on themes in Organizational Behavior area, such as work commitment, organizational changes, meaning of work, organizational cognitions, cognitive maps and social networks in organizational contexts.

Daniela Campos Bahia Moscon holds a PhD and master's in administration from UFBA (Federal University of Bahia), graduated in psychology from the same institution, where she works as an adjunct professor at the School of Administration (EAUFBA). Currently, she is an associate editor of the Psychology of Organizations and Work Journal (RPot - Revista Psicologia Organizaçoes e Trabalho) and member of the scientific committee at National Association of Graduate Studies and Research in Administration.

Giselle Cavalcante Queiroz is a $\mathrm{PhD}$ candidate in administration at the University of São Paulo (USP). She holds a master's in administration and controllership from the Federal University of Ceará (UFC). She is a researcher in the study group People and Work in Different Contexts (GEPeT) at the School of Economics and Business Administration of the University of São Paulo. She is also a researcher in People Management, Work Bonds and Gig Economy. Giselle Cavalcante Queiroz is the corresponding author and can be contacted at: gisellecqueiroz@gmail.com

Associate Editor: Angela Lucas

For instructions on how to order reprints of this article, please visit our website: 